\title{
COPEPODA PARASITICA
}

by Dr. C. B. WILSON.

Pachypygus gibber (Thorell).

Three females belonging to this species were obtained from the branchial cavity of Microcosmus exasperatus at Spanish Water, Curaçao, April 3, 1920. They were not fully grown but measured about $4.50 \mathrm{~mm}$ in length, and the large incubatory pouch was filled with minute eggs.

This is the species described by THORELL and referred by him to the genus Doropygus, but it differs so much from the other species of that genus that both Giesbrecht and SARS recognized it as generically distinct. GIESBRECHT referred it to COSTA's genus Notopterophorus, and SARS created for it the new genus named above, which seems to be correct.

Up to the present time the species has been confined entirely to several species of Ascidians, most commonly Phallusia mentula, and has been found on the coast of Bohuslän by THORELL, in the British Isles by NORMAN and ScotT, along the coast of France by CANU, in the Mediterranean by BuchHoltz, and on both the south and west coasts of Norway by SARS.

It is the largest species of the family Doropygidae and the female sometimes reaches a maximum of $6 \mathrm{~mm}$ in length. It may be recognized by its size and by its unusually robust and strongly arched body.

The present record is the first for the West Indies and also adds a new host to those previously recorded. 